\title{
IGNITION OF COAL DUST FROM THE TOMSK REGION TALOVSKY DEPOSIT BY AIR FLOW
}

\author{
Diana A. Chebochakova, Dmitrii O. Glushkova , Olga E. Lyakhovskaya, Sergey V. Sukhanov \\ National Research Tomsk Polytechnic University, 634050 Tomsk, Russia
}

\begin{abstract}
This paper focuses on the experimental studies of the ignition characteristics of brown coal dust particles from the Tomsk region Talovsky deposit under the conditions of convective heating. The boundary conditions of combustion initiation have been established. The approximation dependence of ignition delay time from the temperature of a heat source has been found.
\end{abstract}

\section{INTRODUCTION}

Coal is a one of major energy sources in a modern world fuel and energy complex [1-4]. Also, this fossil is a unique rock, which is a raw material for the production of different products, from electricity to nanomaterials.

The Talovsky brown coal deposit is a promising alternative source to imported solid fuels for thermal power plants in the Tomsk region of Russian Federation. Its main advantages are the low cost of extraction, processing and transportation. According to preliminary estimates, the volume of coal production can reach 10-15 million tons per year. Nowadays, the option of building a power plant on the outskirts of Tomsk is considered. The power plant will operate with a new type of fuel to generate heat and electricity. The development and implementation of design solutions require the full amount of information about the characteristics of physical and chemical processes occurring during coal ignition [5-8].

The aim of this paper is the experimental study of the ignition of coal dust from the Talovsky deposit during its moving in a stream of heated air.

\section{EXPERIMENTAL SETUP AND PROCEDURE}

Fig. 1 shows a setup for studying coal particles ignition during convective heating.

The setup contains the basic equipment with the following characteristics:

- High-pressure blower Leister Robust. Frequency $50 \mathrm{~Hz}$, power $0.25 \mathrm{~kW}$, air flow 1200 1/min., static pressure $10.8 \mathrm{kPa}$.

- Air heater Leister LHS 61 . Voltage $3 \times 400 \mathrm{~V}$, power $11 \mathrm{~kW}$, maximum air outlet temperature 923 $\mathrm{K}$, maximum ambient temperature $338 \mathrm{~K}$, temperature control on the output, infinitely adjustable heating capacity via potentiometer, minimum air flow rate $1000 \mathrm{l} / \mathrm{min}$.

\footnotetext{
${ }^{a}$ Corresponding author: dmitriyog@tpu.ru
} 
- High-speed video camera Phantom V411. Maximum speed at full resolution of 1280x800 is 4200 fps, maximum speed at reduced resolution of $128 \times 8$ is $600000 \mathrm{fps}, 20 \mu \mathrm{m}$ pixel size, sensor size 25.6x16.0 mm, 12-bit depth, ISO color 2500T, $1 \mu \mathrm{s}$ minimum exposure, 16 GB high-speed internal RAM, Gigabit Ethernet connection.

- Analytical balance OHAUS PA114. Repeatibility (standart deviation) $0.1 \mathrm{mg}$, linearity $0.2 \mathrm{mg}$, tare range 1, stabilization time $3 \mathrm{~s}$, interface RS-232.

- Personal computer Intel Core 2 Duo. Processor i5-3570 CPU $3.4 \mathrm{GHz}$, random-access memory (RAM) 8 GB, read-only memory (ROM) 1 TB, LAN 10/100/1000 Mbit/s.

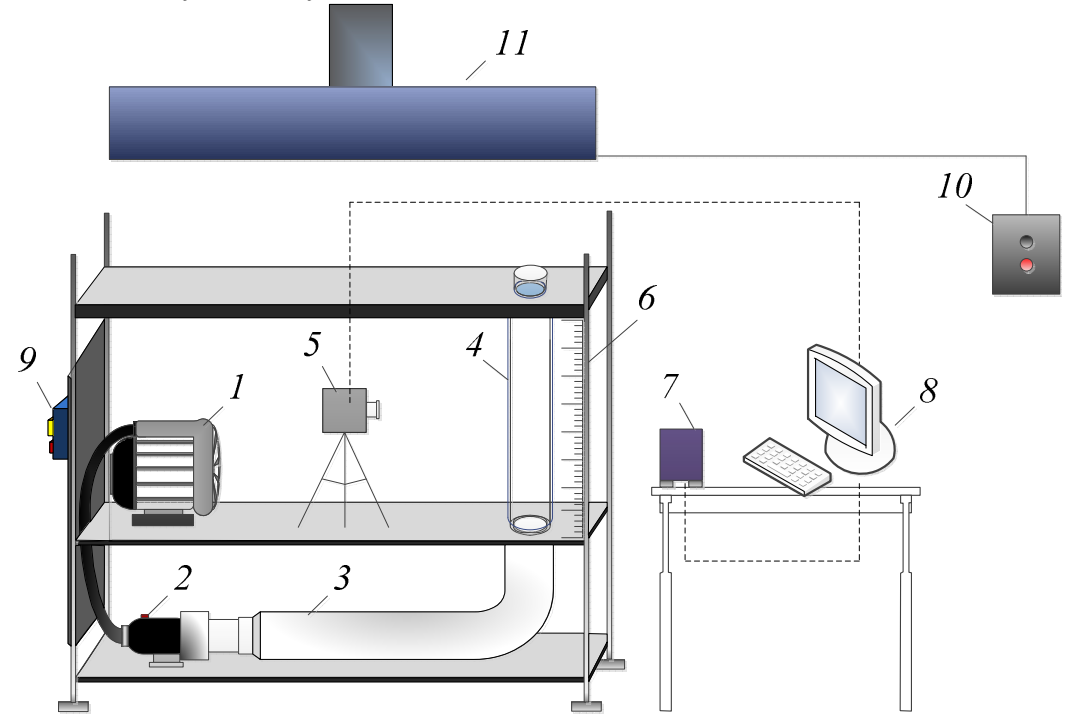

Figure 1. Scheme of a setup: 1 - high-pressure blower; 2 - air heater; 3 - heated air supply channel; 4 - hollow glass cylinder; 5 - high-speed video camera; 6 - ruler; 7 - analytical balance; 8 - computer; 9 - remote control of a heating installation; 10 - remote control of exhaust ventilation; 11 - exhaust ventilation.

The operation principle of the setup (Fig. 1) is as follows. A high-pressure blower 1 delivers air at the ambient temperature to the input of an air heater 2. The air pass through the tubular electric heaters. As a result, the air is heated to a predetermined temperature. The temperature is monitored by thermocuple K. Heated air is fed into the hollow glass cylinder 4 via channel 3 with thermal insulation. A high-speed video camera 5 records fast processes within the cylinder during the induction period. Video saving and processing is performed in a computer 8 with the help of specialized software. A ruler 6 with a sampling scale of $0.1 \mathrm{~mm}$ is used for determining the spatial position of experimental samples during experiments. An analytical balance 7 is used for measuring the mass of the experimental samples. An exhaust ventilation system 10 and 11 removes the gaseous products of carbon thermal decomposition and oxidation to the atmosphere.

Air temperature $T_{p}$ was monitored by a thermocouple measurements method. In preliminary experiments it was found that the dispersion of experimental data increases with decreasing $T_{p}$. Therefore, the number of experiments at a fixed value $T_{p}$ was chosen in view of this feature.

The heater 2 heated air flow to a predetermined temperature (Fig. 1). After stabilizing the temperature in the channel, coal particles were put in a glass cylinder cavity. Video recording starts at the moment of introducing a particle into gas flow. Ignition delay time $t_{d}$ was determined from a video recording and counts until the flame.

The systematic measurement error of air temperature did not exceed $0.8-1.6 \%$. The observational error of $T_{p}$ was $\pm 0.4 \%$. This deviation can be neglected in the analysis, as the temperature of the heat source was not less than $450 \mathrm{~K}$ in the experiments. The random measurement errors of $t_{d}$ were found from the results of the experiments. We conducted a series of experiments for each particle size at the 
fixed value of $T_{p}$. After that, the average values for $T_{p}$ and $t_{d}$, as well as standard deviations have been determined. The analysis of the values of $t_{d}$ established that variation coefficients ranged from $\pm 3.8 \%$ to $\pm 7.5 \%$ in a series of experiments.

We performed experimental studies for dust from the Talovsky lignite deposit. The average size of coal dust particles (Fig. 2) was $80 \mu \mathrm{m}$ and corresponded to the particle size of solid fuel burnt in power boilers.

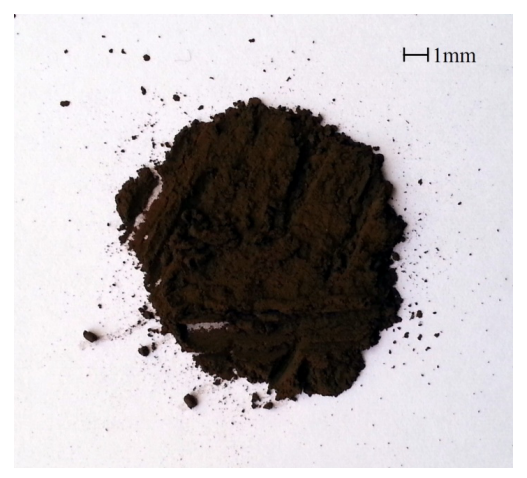

Figure 2. Sample of brown coal dust from the Talovsky deposit (particle size of $80 \mu \mathrm{m}$ ).

\section{Results and discussion}

As a result of data analysis we found the dependence (Fig. 3) of ignition delay time from the temperature of a heat source. The temperature $T_{p}=450 \mathrm{~K}$ is the limit value necessary and sufficient to initiate combustion under the conditions of interaction between coal dust with air flow (at a rate of 4 $\mathrm{m} / \mathrm{s})$.

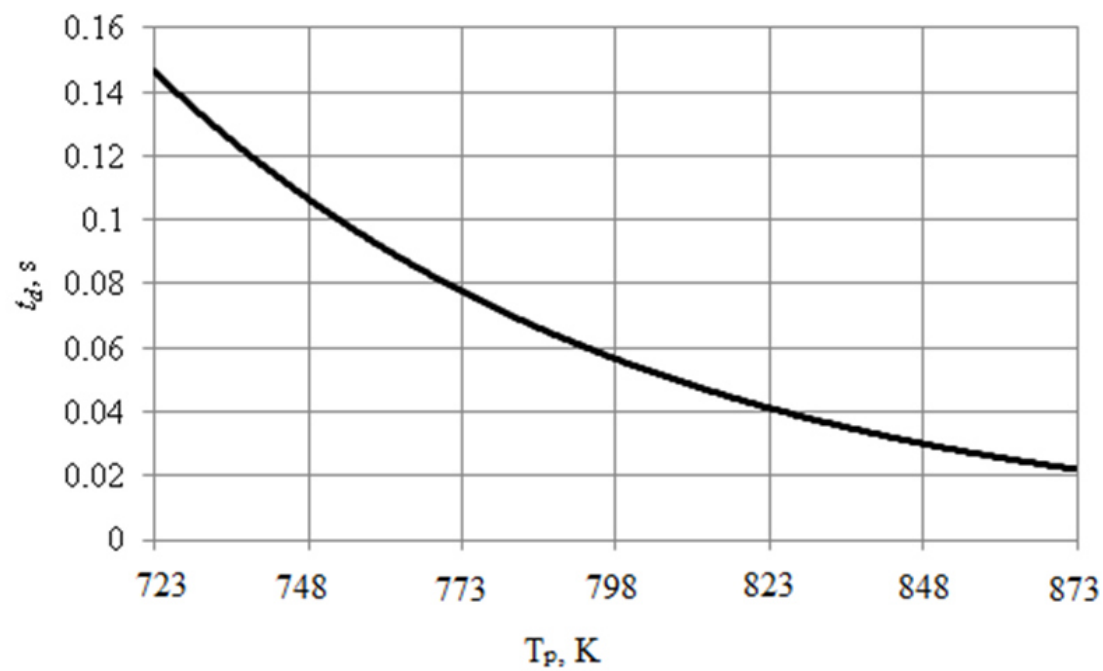

Figure 3. Dependence of coal dust ignition delay time from the air temperature.

The experimental data curve (Fig. 3) is well described by an exponential dependence $t_{d}=f\left(T_{p}\right)$ :

$$
t_{d}=1.393 \cdot 10^{3} \cdot \mathrm{e}^{\left(-0.013 \cdot T_{p}\right)} \text {, s at } 723 \mathrm{~K} \leq T_{p} \leq 873 \mathrm{~K} .
$$

The dependence is well illustrated in the video recordings of the investigated process (Fig. 4). 


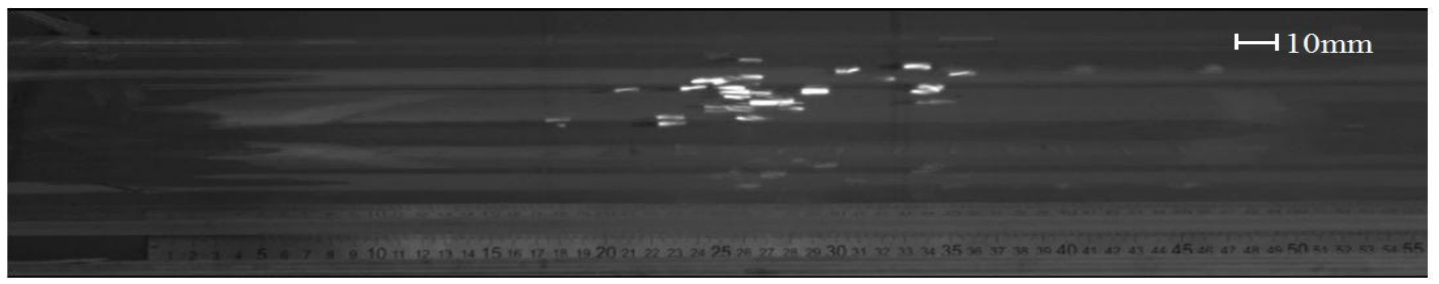

(a)

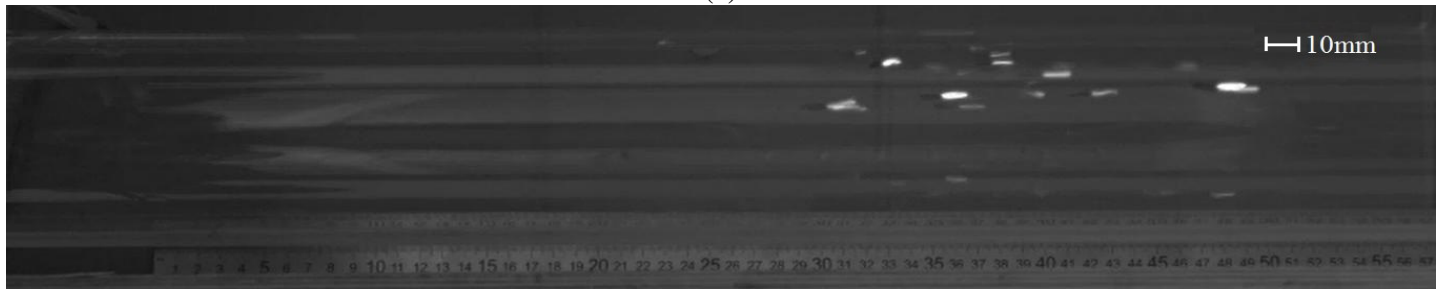

(b)

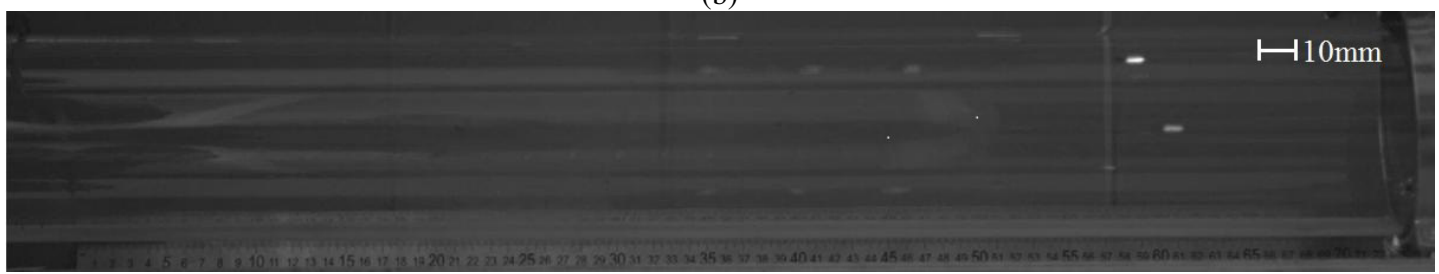

(c)

Figure 4. Coal dust particles ignition under the following conditions: (a) $T_{p}=863 \mathrm{~K}, t_{d}=0.021 \mathrm{~s}$, (b) $T_{p}=823 \mathrm{~K}$, $t_{d}=0.04 \mathrm{~s}$, (c) $T_{p}=753 \mathrm{~K}, t_{d}=0.098 \mathrm{~s}$.

It can be seen (Fig. 4) that if the temperature of an energy source decreases, dust particles pass greater distance until their ignition.

\section{Conclusion}

As a result of experimental studies we established the boundary conditions of the ignition of lignite dust particles from the Tomsk region Talovsky deposit (Russian Federation). We considered particles with the size of $80 \mu \mathrm{m}$ during their motion in convective flow. The approximation dependence of ignition delay time from the temperature of an energy source has been found.

The study was supported by the Russian Science Foundation (project No. 15-19-10003). The experimental setup was developed with the financial support of the program to improve the competitiveness of Tomsk Polytechnic University (project VIU_ENIN_2014).

\section{References}

1. A. Dudzinska, J. Cygankiewicz, Fuel Process. Technol. 137, 109 (2015).

2. S.W. Du, C.P. Yeh, W.H. Chen, C.H. Tsai, J.A. Lucas, Fuel 143, 98 (2015).

3. P.E. Mason, L.I. Darvell, J.M. Jones, M. Pourkashanian, A. Williams, Fuel 95, 50 (2014).

4. V.I. Murko, V.I. Fedyaev, V.I. Karpenok, I.M. Zasypkin, Y.A. Senchurova, A. Riesterer, Therm. Sci. 19, 243 (2015).

5. D.O. Glushkov, P.A. Strizhak, O.V. Vysokomornaya, Therm. Sci. 19, 285 (2015).

6. T. Brosh, D. Patel, D. Wacks, N. Chakraborty, Fuel 145, 50 (2015).

7. B. Goshayeshi, J.C. Sutherland, Combust. Flame 161, 1900 (2014).

8. D.O. Glushkov, G.V. Kuznetsov, P.A. Strizhak, Russ. J. Phys. Chem. B. 9, 242 (2015). 